\title{
LA COORDINACIÓN DE LOS SISTEMAS DE SEGURIDAD SOCIAL EN LA UNIÓN EUROPEA*
}

\author{
Coordination of social security systems \\ in the European Union
}

\author{
Verónica Lidia Martínez Martínez \\ Abogada \\ Academia Mexicana de Derecho de la Seguridad Social \\ marb_cap@hotmail.com \\ doi: http://dx.doi.org/10.18543/ed-65(2)-2017pp177-209
}

Recibido: 10.02 .2017

Aceptado: 28.11.2017

\section{Resumen}

Partiendo de la evolución del sistema de coordinación que impera en la Unión Europea en el ámbito de la seguridad social, en el presente artículo se analizan los principios, la normativa que guían a dicho sistema y la disyuntiva que existe entre los convenios bilaterales y los reglamentos de coordinación, culminando con la referencia a los puntos propuestos por la Comisión Europea para llevar a cabo la revisión de los Reglamentos 883/2004 y 987/2009.

\section{Palabras clave}

Seguridad social, principios, coordinación, reglamento, convenio bilateral.

* Cómo citar / Citation 'Chicago-Deusto' (Autor-fecha / Author-date / Lista de referencias / Reference list entries): Martínez Martínez, Verónica Lidia. 2017. «La coordinación de los sistemas de seguridad social en la Unión Europea». Estudios de Deusto 65, n. ${ }^{\circ}$ 2: 00-00. doi: http://dx.doi.org/10.18543/ed-65(2)-2017pp177-209. 


\section{Abstract}

On the basis of the evolution of the coordination system in the European Union in the field of social security, this article analyzes the principles, the rules that guide the social security system and the dilemma between bilateral agreements and regulations of coordination, culminating in the reference to the points proposed by the European Commission to carry out the revision of Regulations 883/2004 and 987/2009.

\section{Keywords}

Social security, principles, coordination, regulation, bilateral agreement. 


\begin{abstract}
SUMARIO: I. EL SISTEMA DE COORDINACIÓN EN MATERIA DE SEGURIDAD SOCIAL EN LA UNIÓN EUROPEA. II. PRINCIPIOS DEL SISTEMA DE COORDINACIÓN EN MATERIA DE SEGURIDAD SOCIAL. III. NORMATIVA DE LA UNIÓN EUROPEA EN MATERIA DE SEGURIDAD SOCIAL. IV. REGLAMENTOS DE COORDINACIÓN VS. CONVENIOS BILATERALES. V. PROPUESTA DE REVISIÓN AL SISTEMA DE COORDINACIÓN EN MATERIA DE SEGURIDAD SOCIAL. FUENTES DE INFORMACIÓN.
\end{abstract}

\title{
I. EL SISTEMA DE COORDINACIÓN EN MATERIA DE SEGURIDAD SOCIAL EN LA UNIÓN EUROPEA
}

El derecho de la Unión Europea no desempeña una labor de unificación de los sistemas de seguridad social de los Estados miembros. Las principales causas de ello se encuentran en que los diversos sistemas nacionales de seguridad social al ser resultado de un proceso histórico en el que confluyen factores políticos, económicos, sociales y culturales han provocado que los Estados de la Unión se reconozcan dentro de su espacio territorial social como soberanos en la aplicación de sus propia normatividad, existiendo por consecuencia gran renitencia en aceptar otras que provengan de terceros países.

Particularmente, la instauración de cualquier tipo de armonización produce una fuerte oposición, no sólo en los países con modelos de Estados de bienestar más generosos, ante la posible amenaza de reducción de los beneficios sociales, sino también en aquellos en los que la cobertura es menor por miedo a perder competitividad debido al incremento de los costes sociales.

Incluso, debe recordarse que en sus inicios la actual Unión Europea carecía de competencia para regular la materia de seguridad social, limitando su esfera de actuación al ámbito económico. Ante la importancia de lo económico, la política social en general y la seguridad social en particular, tienen un papel secundario, y por ello no se consideran como elementos constitutivos y pilares fundamentales del proceso de integración.

Se asumía que era lógico prescindir en la Comunidad Económica Europea (CEE) de competencias en materia social, en la medida en que la mejora de las condiciones de vida y de empleo debían ser el resultado automático del funcionamiento del mercado interior ${ }^{1}$.

El Tratado de la CEE realizó - para algunos autores desde la teoría ordoliberal alemana- un reparto competencial que reservó lo social a la esfera

${ }^{1}$ Santiago Muñoz Machado y Rafael de Lorenzo, Politica social de la Unión Europea en materia de minusvalias (Escuela Libre, Madrid, 1997), 22. 
decisional de los Estados miembros. En cambio, lo económico se trasladaba al ámbito supranacional, estableciéndose la libertad de circulación y el derecho de la competencia como los pilares fundamentales del proceso de integración ${ }^{2}$.

Concretamente el artículo 51 del Tratado Constitutivo de la CEE se limitaba a establecer que el Consejo de la Unión Europea, a propuesta de la Comisión, adoptaría en materia de seguridad social, las medidas necesarias para el establecimiento de la libre circulación de los trabajadores, creando en especial, un sistema que permitiera garantizar a los trabajadores migrantes y sus derechohabientes la acumulación de todos los períodos tomados en consideración por las distintas legislaciones nacionales para adquirir y conservar el derecho a las prestaciones sociales y al cálculo de éstas, además de garantizar el pago de las prestaciones a las personas que residieran en los territorios de los Estados miembros ${ }^{3}$.

Y a pesar de que de 1974 a 1985, la Comisión Europea empezó a suplir esa laguna competencial con iniciativas legislativas de índole social sobre la base del entonces artículo 100 del Tratado de la $\mathrm{CEE}^{4}$, cierto es que la adopción del Acta de la Unión Europea y el Tratado de la Unión Europea tampoco dotaron de competencia a la Comunidad en el ámbito social.

Las modificaciones realizadas por el Acta Única Europea en la esfera social son escasas y en temas muy específicos, tales como el fomento del diálogo entre los interlocutores sociales a nivel europeo ${ }^{5}$, la protección de la salud y la seguridad de los trabajadores ${ }^{6}$, así como el reforzamiento de la cohesión económica y social a través del apoyo financiero comunitario ${ }^{7}$.

Por su parte, la negativa tajante de Reino Unido a cualquier transferencia de competencia social a la Comunidad provocó que las materias sociales quedaran excluidas del Tratado de la Unión Europea (UE) y fueran relegadas

2 Adoración Guamán Hernández, Estado Social y Unión Europea: el conflicto permanente, [Consulta: 28 de enero de 2017], disponible en $<$ https://www.researchgate.net/ profile/Adoracion_Guaman/publication25/9356604_Estado_social_y_Union_Europea_ el_conflicto_permanente/links/02e7e52b2af0d8a2e60000000.p̄df $>$

${ }_{3}$ Artículo 51 del Tratado de Roma, [Consulta: 28 de enero de 2017], disponible en $<$ https://www.pnsd.msssi.gob.es/pnsd/legislacion/pdfestatal/i12.pdf >

${ }_{4}$ Víctor Bazán y Luis Jimena Quesada, Derechos económicos, sociales y culturales. Cómo se protegen en América latina y en Europa (Astrea, Buenos Aires, 2014), 218-220.

5 Artículo 118 B del Acta Única Europea. [Consulta: 28 de enero de 2017], disponible en <https://www.boe.es/boe/dias/1987/07/03/pdfs/A20172-20182.pdf>

${ }^{6}$ Idem. Artículo 118A del Acta Única Europea.

7 Idem. Artículo 130 A y B del Acta Única Europea. 
a un Acuerdo sobre Política Social ${ }^{8}$, situación que constituyó un enorme paso atrás en el camino de la integración comunitaria en el terreno social.

Así las cosas, la entrada en vigor del Tratado de Maastricht supuso una lamentable distorsión, pues auspicia en el ámbito social dos regímenes jurídicos distintos. De un lado, las disposiciones que al conformar el Título VIII, Cap. I del Tratado de la UE resultaban aplicables a todos los Estados miembros $^{9}$. De otro, las disposiciones del Protocolo sobre la política social anexo al Tratado de la UE aplicables a todos los que en aquella época eran miembros $^{10}$, a excepción del Reino Unido ${ }^{11}$.

Este panorama y la ausencia de una verdadera identidad europea que hiciera posible la aplicación de esquemas de solidaridad ${ }^{12}$ desembocó en la $^{2}$ adopción de un régimen comunitario de coordinación de los disimiles sistemas nacionales de seguridad social organizados y financiados por los Estados, cuyo objetivo principal era remover las trabas a la libre circulación de los trabajadores ${ }^{13}$.

${ }^{8}$ El Protocolo 14 sobre Política Social se incorpora como anexo al Tratado de la Unión Europea.

9 Con el Tratado de Maastricht nace la Unión Europea y estableció la ciudadanía de la Unión

${ }^{10}$ Los once Estados miembros eran el Reino de Bélgica, el Reino de Dinamarca, la República Federal de Alemania, la República Helénica, el Reino de España, la República Francesa, Irlanda, la República Italiana, el Gran Ducado de Luxemburgo, el Reino de los Países Bajos y la República Portuguesa.

${ }^{11}$ El 2 de octubre de 1997 cuando se firma el Tratado de Ámsterdam, Reino Unido aceptó el Protocolo sobre Política Social. El Tratado de Ámsterdam integra en el Título XI TCE aquellas disposiciones que conformaban dicho Acuerdo sobre Política Social. En consecuencia, con este Tratado quedan definitivamente aglutinadas bajo un mismo Capítulo todas las disposiciones de Derecho originario en materia de política social. El Tratado de Ámsterdam - que entró en vigor el $1^{\circ}$ de mayo de 1999- establece en el artículo 49 la exigencia del respeto de los derechos humanos como condición indispensable para que un Estado europeo pudiera solicitar el ingreso como miembro de la Unión. Este tratado introduce bases habilitantes europeas para la adopción de legislación en diversos ámbitos sociales y se extiende a través del Tratado de Niza de 26 de febrero de 2001.

12 Justo Corti Varela, «La propuesta de seguro de desempleo europeo. Estado de la cuestión», Ana María Chocrón Giráldez et al., (Coord.), El derecho del trabajo y la seguridad social en la encrucijada. Retos para la disciplina laboral (Laborum, Murcia, 2015), 127.

${ }^{13}$ La libertad de circulación se encuentra reconocido en los Tratados Fundacionales de la Comunidad Europea. Así, tenemos que el principio básico consagrado en el Tratado de Roma es la eliminación de los obstáculos a la libre circulación de las personas entre los Estados miembros. Disposición relativa a la libre circulación de los trabajadores estaba contemplada en el artículo 39, de acuerdo a la numeración establecida por el Tratado de Maastricht por el que se constituyó la Comunidad Europea 
Con los Reglamentos 3 y 4 se inaugura el ejercicio de las competencias normativas de la Comunidad en desarrollo de la materia social ${ }^{14}$, como un puente jurídico que va a permitir el paso de un sistema jurídico a otro, de modo que los derechos adquiridos o en vía de adquisición en un Estado pueden invocarse en otro Estado como si se hubieran producido en el primero ${ }^{15}$. De esta manera, la coordinación de los sistemas de seguridad social favorece el respeto y exigibilidad de las prestaciones sociales, además de distribuir las cargas entre los distintos regímenes nacionales.

Empero, lo que indudablemente ha marcado las notas y directrices que caracterizan a la coordinación/articulación ${ }^{16}$ ha sido la jurisprudencia del Tribunal de Luxemburgo. Así, del contenido de las sentencias del Máximo Tribunal de la UE se infiere que la coordinación al no implicar unificación ni armonización de los sistemas de Seguridad Social, no conlleva su la deroga-

(Tratado CE). Antes de esta etapa, es decir, hasta el 30 de noviembre de1993, dicha disposición figuraba en el art. 48 del Tratado CE. Por su parte, los artículos 20 del Tratado de Funcionamiento de la Unión Europea (TFUE) reconoce a los ciudadanos de la Unión el derecho a circular y residir libremente en el territorio de los Estados miembros. El artículo 45 del TFUE garantiza la libre circulación de los trabajadores, reconocido como La libertad de circulación es también un derecho fundamental consagrado en el artículo 15, apartado 2 de la Carta de los Derechos Fundamentales de la Unión Europea y reconocido en el Reglamento CEE n. ${ }^{\circ}$ 1612/68 Reglamento (CEE) de 15 de octubre de 1968 relativo a la libre circulación de los trabajadores dentro de la Comunidad; el Reglamento (CEE) N. ${ }^{\circ}$ 1408/71 del Consejo relativo a la aplicación de los regímenes de seguridad social a los trabajadores por cuenta ajena, a los trabajadores por cuenta propia y a los miembros de su familia que se desplazan dentro de la Comunidad; la Directiva 2004/38/CE del Parlamento Europeo y el Consejo de 29 de abril de 2004 relativa al derecho de los ciudadanos de la Unión y de los miembros de sus familias a circular y residir libremente en el territorio de los Estados miembros, por la que se modifica el Reglamento (CEE) $n^{\circ} 1612 / 68$ y se derogan las Directivas 64/221/CEE, 68/360/CEE, 72/194/CEE, 73/148/CEE, 75/34/CEE, 75/35/CEE, 90/364/CEE, 90/365/ CEE y 93/96/CEE, así como la jurisprudencia del Tribunal de Justicia de la Unión Europea.

${ }^{14}$ Javier Gárate Castro, Transformaciones en las normas comunitarias sociales, en Los mercados laborales y las políticas sociales de Europa. XX Congreso Nacional de Derecho de Trabajo y de la Seguridad Social, Logroño 28 y 29 de mayo de 2009 (Ministerio de Trabajo e Inmigración. Subdirección General de Información Administrativa y Publicaciones, Madrid, 2010), 25.

15 Cristina Sánchez-Rodas Navarro, La aplicación del derecho comunitario a las prestaciones especiales no contributivas (Comares, Granada, 1997), 2.

${ }^{16}$ En la doctrina existe un sector que propone abandonar el clásico término de coordinación, y en su lugar proponen utilizar la expresión articulación. Vid. Cfr. José María Miranda Boto, «El Estadio Previo: Algunos Problemas Terminológicos de la Seguridad Social Comunitaria», VV.AA., El Reglamento Comunitario. Nuevas Cuestiones. Viejos Problemas (Laborum, Murcia, 2008), 26-28. 
ción, reforma, o modificación, sino que permite su subsistencia con todas sus peculiaridades, al tiempo que tampoco veda las competencias soberanas de los Estados para legislar en el ámbito de la seguridad social ${ }^{17}$.

A partir de la regla impuesta en la jurisprudencia del Tribunal de Luxemburgo que dicta que la libertad de movimiento no equivale a un libre acceso a los sistemas de seguridad social de otro Estado miembro; las normas de coordinación al determinar el sistema de seguridad social que opera en situaciones que afecta a más de un Estado miembro, cumplen con la finalidad de brindar certeza y seguridad jurídica ante el ejercicio del derecho fundamental a la libre circulación de trabajadores, y así evitar la presencia de los conflictos de nomas de carácter positivo o negativo. El surgimiento del primer tipo de controversias tiene lugar cuando varias normas nacionales de seguridad social pueden aplicarse a un mismo sujeto. Por el contrario, los conflictos normativos de carácter negativo se presentan cuando ninguna norma nacional resulta competente para regular el supuesto concreto $^{18 .}$

\section{PRINCIPIOS DEL SISTEMA DE COORDINACIÓN EN MATERIA DE SEGURIDAD SOCIAL.}

Normalmente los reglamentos comunitarios y la jurisprudencia del Tribunal de Justicia de la UE, suelen establecer reglas y principios para evitar que los trabajadores estén asegurados en más de un Estado miembro o carezcan de los beneficios de un sistema de seguridad social. Los principios básicos sobre los que descansa el sistema de coordinación de las legislaciones internas son:

a. No discriminación e igualdad de trato. Este principio - que resulta obligatorio para las autoridades públicas y entidades privadas- opera en dos planos, el primero de ellos, derivado del ejercicio del derecho fundamental a la libre circulación de trabajadores, posibilita a que los operarios sujetos a la legislación del Estado miembro en el que ejercen su actividad laboral tengan los mismos beneficios prestacionales, así como derechos y obligaciones que los nacionales de ese Estado.

${ }^{17}$ Cristina Sánchez-Rodas Navarro, «Sinopsis del Reglamento 883/2004 y del Convenio Multilateral Iberoamericano de Seguridad Social», Ana María Chocrón Giráldez et al. (Coord.), El derecho del trabajo y la seguridad social en la encrucijada. Retos para la disciplina laboral (Laborum, Murcia, 2015), 184.

18 Rene Bonnet, Conflits entre les droits nationaux et les instruments internationaux dans Ie domaine de la securite sociale (Techniques, Juris-Classeur, 1993), Fascicule 578,2 . 
El artículo 69.4 del Tratado Constitutivo de la Comunidad Europea del Carbón y e1 Acero firmado en París el 18 de abril de $1951^{19}$, así como los artículos 18 (antiguo artículo 12 TCE) ${ }^{20}$ y 45 del Tratado de Funcionamiento de la Unión Europea ${ }^{21}$ (antiguo artículo 39.2 TCE) garantizan la igualdad de trato para todos los trabajadores de la UE dentro de los Estados miembros.

El objetivo perseguido por este conjunto de disposiciones es evitar que los trabajadores migrantes -por el simple hecho de no ostentar la nacionalidad del Estado cuya legislación les resulta aplicable- puedan encontrarse en una situación menos ventajosa que los propios nacionales ${ }^{22}$.

19 Artículo 69.4 del Tratado Constitutivo de la Comunidad Europea del Carbón y e1 Acero. Los Estados miembros prohibirán toda discriminación en la retribución y en las condiciones de trabajo entre trabajadores nacionales y trabajadores inmigrados, sin perjuicio de las medidas especiales referentes a los trabajadores fronterizos; en particular, tratarán de buscar entre sí cuantas soluciones sigan siendo necesarias a fin de que las disposiciones relativas a la seguridad social no constituyan un obstáculo para los movimientos de la mano de obra. [Consulta: 20 de enero de 2017], disponible en $<$ https://www.boe.es/legislacion/enlaces/documentos/ue/Tratados(0397-0475).pdf>

20 Artículo 18 TFUE. En el ámbito de aplicación de los Tratados, y sin perjuicio de las disposiciones particulares previstas en los mismos, se prohibirá toda discriminación por razón de la nacionalidad. [Consulta: 24 de enero de 2017], disponible en $<$ https:// www.boe.es//doue/2010/083/Z00047-00199.pdf>

${ }^{21}$ Idem. Artículo 45 del TFUE.

1. Quedará asegurada la libre circulación de los trabajadores dentro de la Unión.

2. La libre circulación supondrá la abolición de toda discriminación por razón de la nacionalidad entre los trabajadores de los Estados miembros, con respecto al empleo, la retribución y las demás condiciones de trabajo.

3. Sin perjuicio de las limitaciones justificadas por razones de orden público, seguridad y salud públicas, la libre circulación de los trabajadores implicará el derecho:

a) de responder a ofertas efectivas de trabajo;

b) de desplazarse libremente para este fin en el territorio de los Estados miembros;

c) de residir en uno de los Estados miembros con objeto de ejercer en él un empleo, de conformidad con las disposiciones legales, reglamentarias y administrativas aplicables al empleo de los trabajadores nacionales;

d) de permanecer en el territorio de un Estado miembro después de haber ejercido en él un empleo, en las condiciones previstas en los reglamentos establecidos por la Comisión.

4. Las disposiciones del presente artículo no serán aplicables a los empleos en la administración pública.

${ }^{22}$ Cristina Sánchez-Rodas Navarro, «Análisis crítico del capítulo 8 del Reglamento 883/2004», Revista General de Derecho del Trabajo y Seguridad Social, núm. 32, 2012. 
Por su parte, el segundo aspecto de este principio reside en asegurar la igualdad entre hombres y mujeres en el ámbito de la seguridad social. De manera general, los principios de igualdad entre hombres y mujeres así como el de no discriminación se encuentran reconocidos en el Derecho originario en los artículos 2 y 3, apartado 3, primer párrafo del Tratado de la Unión Europea $^{23}$, en los artículos $8^{24}, 10^{25}, 19^{26}$, del Tratado de Funcionamiento de la Unión Europea (TFUE) y en el artículo 21 de la Carta de los Derechos Fundamentales de la Unión Europea ${ }^{27}$, cuya aplicación debe darse dentro de los límites que dispone su artículo 51 .

${ }^{23}$ Artículos 2 y 3, apartado 3 del Tratado de la Unión Europea ${ }^{A}$ rtículo 2 La Unión se fundamenta en los valores de respeto de la dignidad humana, libertad, democracia, igualdad, Estado de Derecho y respeto de los derechos humanos, incluidos los derechos de las personas pertenecientes a minorías. Estos valores son comunes a los Estados miembros en una sociedad caracterizada por el pluralismo, la no discriminación, la tolerancia, la justicia, la solidaridad y la igualdad entre mujeres y hombres. Artículo 3 (antiguo artículo 2 TUE) La Unión combatirá la exclusión social y la discriminación y fomentará la justicia y la protección sociales, la igualdad entre mujeres y hombres, la solidaridad entre las generaciones y la protección de los derechos del niño. [Consulta: 2 de febrero de 2017], disponible en <http://www.boe.es/doue/2010/083/Z00013-00046.pdf>

${ }^{24}$ Artículo 8 TFUE En todas sus acciones, la Unión se fijará el objetivo de eliminar las desigualdades entre el hombre y la mujer y promover su igualdad. [Consulta: 24 de enero de 2017], disponible en <https://www.boe.es//doue/2010/083/Z00047-00199.pdf>

${ }^{25}$ Idem. Artículo 10. En la definición y ejecución de sus políticas y acciones, la Unión tratará de luchar contra toda discriminación por razón de sexo, raza u origen étnico, religión o convicciones, discapacidad, edad u orientación sexual.

${ }^{26}$ Idem. Artículo 19. Sin perjuicio de las demás disposiciones de los Tratados y dentro de los límites de las competencias atribuidas a la Unión por los mismos, el Consejo, por unanimidad con arreglo a un procedimiento legislativo especial, y previa aprobación del Parlamento Europeo, podrá adoptar acciones adecuadas para luchar contra la discriminación por motivos de sexo, de origen racial o étnico, religión o convicciones, discapacidad, edad u orientación sexual. 2. No obstante lo dispuesto en el apartado 1, el Parlamento Europeo y el Consejo podrán adoptar, con arreglo al procedimiento legislativo ordinario, los principios básicos de las medidas de la Unión de estímulo, con exclusión de toda armonización de las disposiciones legales y reglamentarias de los Estados miembros, para apoyar las acciones de los Estados miembros emprendidas con el fin de contribuir a la consecución de los objetivos enunciados en el apartado 1.

${ }^{27}$ La Carta de los Derechos Fundamentales de la Unión Europea no se ha incorporado directamente al Tratado de Lisboa, pero el artículo 6, apartado 1, del TUE le atribuye carácter jurídicamente vinculante, confiriéndole así el mismo valor jurídico que los Tratados. Artículo 21. 1. Se prohíbe toda discriminación, y en particular la ejercida por razón de sexo, raza, color, orígenes étnicos o sociales, características genéticas, lengua, religión o convicciones, opiniones políticas o de cualquier otro tipo, pertenencia a una minoría nacional, patrimonio, nacimiento, discapacidad, edad u orientación sexual. 2. Se prohíbe toda discriminación por razón de nacionalidad en el ámbito de aplicación del Tratado constitutivo de la Comunidad Europea y del Tratado de la Unión Europea y sin perjuicio 
En el Derecho derivado, la igualdad entre hombres y mujeres en el ámbito de la seguridad social, además de garantizarse por el Reglamento 883/2004, ${ }^{28}$ se fortalece mediante las siguientes directivas ${ }^{29}$ :

- Directiva 79/7/CEE, del Consejo de 19 de diciembre de 1978, relativa a la aplicación progresiva del principio de igualdad de trato entre hombres y mujeres en materia de seguridad social [DO L 6 de 10 de enero de 1979].

- Directiva 2010/41/UE del Parlamento Europeo y del Consejo, de 7 de julio de 2010, sobre la aplicación del principio de igualdad de trato entre hombres y mujeres que ejercen una actividad autónoma [DO L 180 de 15 de julio de 2010$]^{30}$.

- Directiva 92/85/CEE, del Consejo, de 19 de octubre de 1992, relativa a la aplicación de medidas para promover la mejora de la seguridad y de la salud en el trabajo de la trabajadora embarazada, que haya dado a luz o esté en período de lactancia [DO L 348 de 28 de noviembre de $1992]^{31}$.

- Directiva 2000/78/CE de 27 de noviembre de 2000, relativa al establecimiento de un marco general para la igualdad de trato en el empleo y la ocupaci6n. [DO L 303 de 2 de diciembre de 2000].

de las disposiciones particulares de dichos Tratados. [Consulta: 22 de enero de 2017], disponible en <http://www.europarl.europa.eu/charter/pdf/text_es.pdf>

${ }^{28}$ Artículo 4 del Reglamento 883/2004. Las personas a las cuales sean aplicables las disposiciones del presente Reglamento podrán acogerse a los beneficios y estarán sujetas a las obligaciones de la legislación de todo Estado miembro en las mismas condiciones que los nacionales de dicho Estado, salvo disposición en contrario del presente Reglamento. Artículo 7 del Reglamento 883/2004 Salvo disposición en contrario del presente Reglamento, las prestaciones en metálico debidas en virtud de la legislación de uno o de varios Estados miembros o del presente Reglamento no podrán sufrir ninguna reducción, modificación, suspensión, supresión o confiscación por el hecho de que el beneficiario o los miembros de su familia residan en un Estado miembro distinto de aquél en que se encuentra la institución deudora. [Consulta: 27 de enero de 2017], disponible en $<$ eur-lex. europa.eu/LexUriServ/LexUriServ.do?uri=OJ:L:2004:166:0001:0123:es:PDF>

${ }_{29}$ Víctor Fernando Manrique López, «La normativa comunitaria actualmente vigente en la Unión Europea», Estudios de Deusto, Vol. 54/1 (enero-junio 2006), 107-108.

${ }^{30}$ La Directiva 2010/41/UE deroga la Directiva 86/613/CEE del Consejo de 11 de diciembre de 1986 relativa a la aplicación del principio de igualdad de trato entre hombres y mujeres que ejercen una actividad autónoma, incluidas las actividades agrícolas, así como la protección de la maternidad (DO L 359 de 19 de diciembre de 1986).

${ }^{31}$ La directiva 92/85/CEE ha sido por modificada por la Directiva 2007/30/CE, de 28 de junio de 2007 (DO L 165 de 27 de junio de 2007) y la Directiva 2014/27/UE, de 25 de marzo de 2014 (DO L 65 de 5 de marzo de 2014). 
- Directiva 2004/113/CE del Consejo de 13 de diciembre de 2004 por la que se aplica el principio de igualdad de trato entre hombres y mujeres al acceso de bienes, servicios y suministros ${ }^{32}$ [DO L 373 de 21 de diciembre de 2004].

- Directiva 2006/54/CE del Parlamento Europeo y del Consejo, de 5 de julio de 2006, relativa a la aplicación del principio de igualdad de oportunidades e igualdad de trato entre hombres y mujeres en asuntos de empleo y ocupación (refundición) [DO L 204 de 26 de julio de 2006] $]^{33}$.

- Directiva 2010/18/UE del Consejo, de 8 de marzo de 2010, por la que se aplica el Acuerdo marco revisado sobre el permiso parental, celebrado por Businesseurope, la UEAPME, el CEEP y la CES [DO L 68 de 18 de marzo de 2010] $]^{34}$.

- Directiva 2010/41/UE, de 7 de julio de 2010, en la que se establecen objetivos para la aplicación del principio de igualdad de trato entre hombres y mujeres que ejercen una actividad autónoma, incluidas las actividades agrícolas, así como sobre la protección de la maternidad [DO L 180 de 15 de julio de 2010] $]^{35}$.

${ }^{32}$ En la sentencia Test-Achats de 1 de marzo de 2011 (asunto C-236/09), el Tribunal de la UE declaró inválido el artículo 5, apartado 2, de la Directiva 2004/113/CE por ser contrario al principio de igualdad de trato entre hombres y mujeres en el acceso a bienes y servicios y su suministro. Sentencia del Tribunal de Justicia de la Unión Europea. [Consulta: 21 de enero de 2017], disponible en $<$ https://curia.europa.eu/juris/showPdf.jsfjsessi onid=9ea7d0f130d5b4881931b9c049508d97bb2f7bc97c4f.e34KaxiLc3eQc40LaxqMbN 4OchiLe 0 ?text $=\&$ docid $=96853 \&$ pageIndex $=0 \&$ doclang $=$ ES \&mode $=1$ st $\&$ dir $=\&$ occ $=$ first \&part $=1 \&$ cid $=654345>$

${ }^{33}$ La Directiva 2006/54/CE derogó la Directiva 75/117/CEE del Consejo, de 10 de febrero de 1975, relativa a la aproximación de las legislaciones de los Estados miembros que se refieren a la aplicación del principio de igualdad de retribución entre los trabajadores y trabajadoras; la Directiva 76/207/CEE del Consejo, de 9 de febrero de 1976, relativa a la aplicación del principio de igualdad de trato entre hombres y mujeres en lo que se refiere al acceso al empleo, a la formación y a la promoción profesionales y a las condiciones de trabajo, La Directiva 2002/73/CEE del Parlamento Europeo y Consejo de 23 de septiembre de 2002, que modificó la Directiva 76/207/CEE; la Directiva 86/378/CEE, de 24 de julio de 1986, sobre igualdad de trato entre hombres y mujeres en los regímenes profesionales de seguridad social. modificada por la Directiva 96/97/CE del Consejo, de 20 de diciembre de 1996 y deroga la Directiva 97/80/CE del Consejo, de 15 de diciembre de 1997, relativa a la carga de la prueba en los casos de discriminación por razón de sexo, ampliada al Reino Unido por la Directiva 98/52/CE, de 13 de julio de 1998. Actualmente, el Parlamento trabaja en la revisión de esta Directiva en lo referente a las disposiciones sobre la igualdad de retribución

${ }^{34}$ La Directiva 2010/18/UE derogó la Directiva 96/34/CE del Consejo, de 3 de junio de 1996, relativa al Acuerdo Marco sobre el Permiso Parental celebrado por la UNICE, el CEEP y la CES.

35 La Directiva 2010/41/UE derogó la Directiva 86/613/CEE del Consejo 
Por supuesto que un factor determinante que ha contribuido al fortalecimiento del principio de igualdad en el campo de la seguridad social ha sido la labor desplegada por las instituciones de la UE, particularmente la actividad jurisdiccional del Tribunal de Luxemburgo ${ }^{36}$ y el trabajo emprendido por el Parlamento Europeo y el Consejo con acciones tales como el Compromiso estratégico para la igualdad de genero 2016-2019, cuyo uno de sus pilares fundamentales es combatir la desigualdad que impera en las pensiones entre hombres y mujeres.

b. Unicidad. Conforme a este principio cada beneficiario está cubierto por la legislación de un solo Estado miembro, lo que a su vez implica que sólo un Estado miembro tiene la competencia para deducir las cotizaciones sociales.

La finalidad de este postulado - reconocido en el artículo 11, apartado 1 del Reglamento 883/2004-37 es evitar que alguien pueda obtener ventajas indebidas por ejercer el derecho a la libre circulación, debido a que el hecho de cotizar a los sistemas de seguridad social obligatorios en dos o más Estados miembros durante el mismo período de seguro, no genera el derecho a percibir varias prestaciones de la misma naturaleza ${ }^{38}$.

${ }^{36}$ Sentencia Bilka de 13 de mayo de 1986 (asunto C-170/84, [Consulta: 2 de enero de 2017], Disponible en http://eur-lex.europa.eu/legal-content/ES/TXT/?uri=CELEX\%3A6 1993CJ0128. Sentencia Barber de 17 de mayo de 1990 (asunto C-262/88), [Consulta: 2 de enero de 2017], Disponible en: http://eur-lex.europa.eu/legal-content/ES/TXT/HTML/?uri= CELEX:61993CJ0057\&from=ES. Sentencia Test-Achats de 1 de marzo de 2011 (asunto C-236/09): a STJUE de 3 de septiembre de 2014, asunto C-318/13, considera contrario a la Directiva 79/7/CEE el uso de un factor de cálculo de una indemnización a tanto alzado, basado en la esperanza de vida media en función del sexo, al no estar expresamente exceptuada esa prestación del ámbito de la Directiva, jurisprudencia recogida en la STJUE de 1 de marzo de 2011 (asunto C-236/09) en la que se rechazó la posibilidad de establecer diferencias en función del sexo en las primas y prestaciones de seguros, por ser contraria, en este caso, a la Directiva 2004/113/CE. [Consulta: 21 de enero de 2017], Disponible en: https:// curia.europa.eu/juris/showPdf.jsfjsessionid=9ea $7 d 0 f 130 d 5 b 4881931 b 9 c 049508 d 97 b b 2 f 7$ bc97c4f.e34KaxiLc3eQc40LaxqMbN4OchiLe0?text $=\&$ docid $=96853 \&$ pageIndex $=0 \&$ docl ang $=E S \&$ mode $=l$ st \&dir $=\& o c c=$ first $\&$ part $=1 \&$ cid $=654345$

37 Reglamento (CE) n. ${ }^{\circ} 883 / 2004$ estipula en su artículo 11, apartado 1. 1. Las personas a las cuales sea aplicable el presente Reglamento estarán sometidas a la legislación de un único Estado miembro. Esta legislación será determinada con arreglo al presente título. [Consulta: 3 de febrero de 2017], disponible en <eur-lex.europa.eu/LexUriServ.do?uri=O J:L:2004:166:0001:0123:es:PDF>

${ }^{38}$ El principio de unicidad o exclusividad no es absoluto. En numerosos casos, las personas que reciben una pensión deben pagar cotizaciones del seguro de enfermedad en otro Estado miembro distinto del Estado de residencia. Respecto de este último punto tienen aplicabilidad los artículos 23 y 30 del Reglamento 883/2004 así como el artículo 30 del Reglamento (CE) n. ${ }^{\circ}$ 987/2009 
c. Territorialidad en la determinación de la ley aplicable. Conforme al principio lex loci labori -plasmado en el artículo 11, apartado 3, letra a) del Reglamento 883/2004-, normalmente los trabajadores están sujetos a la legislación del Estado miembro en el que prestan sus servicios laborales.

Este postulado puede admitir algunas excepciones y matizaciones como a continuación se advierte en los casos siguientes:

\begin{tabular}{|c|c|}
\hline Tipo de actividad & Estado competente \\
\hline $\begin{array}{l}\text { Trabajador fronterizo que } \\
\text { ejerce actividad por cuenta } \\
\text { ajena o por cuenta propia. }\end{array}$ & $\begin{array}{l}\text { Estado miembro donde se ejerce la actividad } \\
\text { profesional [articulo 11(3) a del Reglamento } \\
883 / 2004 \text { ] }\end{array}$ \\
\hline $\begin{array}{l}\text { Trabajador en la adminis- } \\
\text { tración pública. }\end{array}$ & $\begin{array}{l}\text { Estado miembro de la administración que le ocupa } \\
\text { [artículo 11(3) b del Reglamento 883/2004] }\end{array}$ \\
\hline $\begin{array}{l}\text { Persona que trabaja a } \\
\text { bordo de un buque. }\end{array}$ & $\begin{array}{l}\text { Estado miembro del pabellón que enarbole el } \\
\text { buque o Estado del empleador, si la persona reside } \\
\text { en dicho Estado [articulo 11(4) del Reglamento } \\
\text { 883/2004] }\end{array}$ \\
\hline Persona desplazada. & $\begin{array}{l}\text { Estado miembro donde se origina el desplaza- } \\
\text { miento, a condición de que la duración previsible } \\
\text { de dicho trabajo no exceda de veinticuatro meses } \\
\text { y de que dicha persona no sea sustituida por otra } \\
\text { [articulo } 12 \text { del Reglamento } 883 / 2004 \text { ] }\end{array}$ \\
\hline $\begin{array}{l}\text { Persona que ejerce una } \\
\text { actividad por cuenta ajena } \\
\text { en dos Estados miembros o } \\
\text { más, por ejemplo: } \\
\text { - dos actividades o más a } \\
\text { tiempo parcial; } \\
\text { - personal itinerante o } \\
\text { navegante del transporte } \\
\text { internacional; } \\
\text { - teletrabajo en alternan- } \\
\text { cia. }\end{array}$ & $\begin{array}{l}\text { Estado miembro de residencia, si dicha persona } \\
\text { ejerce una parte sustancial de su actividad en } \\
\text { dicho articulo Estado miembro o si depende de } \\
\text { varias empresas o de varios empresarios que } \\
\text { tengan su sede o su domicilio en diferentes } \\
\text { Estados miembros [artículo 13(1) del Reglamento } \\
883 / 2004 \text { ] } \\
\text { Estado miembro en el que la empresa o el } \\
\text { empresario que la ocupa tenga su sede o su } \\
\text { domicilio, siempre que dicha persona no ejerza } \\
\text { una parte sustancial de sus actividades en el } \\
\text { Estado miembro de residencia. } \\
\text { El hecho de alcanzar un porcentaje inferior al } 25 \\
\% \text { en lo que concierne al tiempo de trabajo y/o la } \\
\text { remuneración será un indicador de que una parte } \\
\text { sustancial de las actividades no se ejerce en el } \\
\text { Estado miembro de que se trate. [art. 14(8) del } \\
\text { Reglamento 987/2009] }\end{array}$ \\
\hline
\end{tabular}




\begin{tabular}{|l|l|}
\hline \multicolumn{1}{|c|}{ Tipo de actividad } & \multicolumn{1}{c|}{ Estado competente } \\
\hline $\begin{array}{l}\text { Persona que ejerce una acti- } \\
\text { vidad por cuenta propia en } \\
\text { dos o más Estados } \\
\text { miembros }\end{array}$ & $\begin{array}{l}\text { Estado miembro de residencia, si ejerce una parte } \\
\text { sustancial de su actividad en él, o el Estado } \\
\text { miembro en el que se encuentra el centro de } \\
\text { interés de sus actividades [articulo 13(2) del } \\
\text { Reglamento 883/2004. }\end{array}$ \\
\hline $\begin{array}{l}\text { Persona que ejerce } \\
\text { actividad por cuenta ajena } \\
\text { y actividad por cuenta } \\
\text { propia en diferentes } \\
\text { Estados miembros. }\end{array}$ & $\begin{array}{l}\text { Estado miembro en el que ejerce una actividad por } \\
\text { cuenta ajena [articulo 13(3) Reglamento } \\
883 / 2004]\end{array}$ \\
\hline $\begin{array}{l}\text { Persona que ejerce una acti- } \\
\text { vidad por cuenta propia en } \\
\text { dos o más Estados } \\
\text { miembros. }\end{array}$ & $\begin{array}{l}\text { Estado miembro de residencia, si ejerce una parte } \\
\text { sustancial de su } \\
\text { actividad en él, o el Estado miembro en el que se } \\
\text { encuentra el centro de interés de sus actividades } \\
\text { [articulo 13(2) del Reglamento 883/2004] }\end{array}$ \\
\hline $\begin{array}{l}\text { Jubilados } \\
\text { Están sometidos, en principio, a la seguridad } \\
\text { social del país de residencia [articulo 11(3) del } \\
\text { Reglamento 883/2004] }\end{array}$ \\
\hline
\end{tabular}

Cuadro 1. Tomado de Distler Katrin y Essers, Ger, Guía del trabajador móvil europeo. Bélgica, Confederación Europea de Sindicatos, 2011, pp. 18-19

d. Subsidiariedad de la intervención normativa comunitaria. Por disposición de este principio, recogido en el artículo 151 del TFUE, los Estados miembros -sobre la base de respetar el Derecho Comunitario y las disposiciones del Tratado CE relativas a la libre circulación de trabajadores- ${ }^{39}$ conservar la facultad reconocida de definir las directrices fundamentales de su sistema de seguridad social.

39 Sentencia 18 de abril de 2002. Asunto C-290/00. Johann Franz Duchon vs. Pensionsversicherungsanstalt der Angestellten, [Consulta: 31 de enero de 2017], disponible en <http://eur-lex.europa.eu/legal-content/ES/TXT/PDF/?uri=CELEX:62000CJ0290\&fr om=ES $>$. Sentencia 13 de junio de 1996. Asunto C-170/95. Office National de l'emploi vs. Calogero Spataro, [Consulta: 31 de enero de 2017], disponible en $<$ http://eur-lex.europa.eu/legal-content/ES/TXT/PDF/?uri=CELEX:61995CJ0170\&from=EN $>$. Sentencia 8 de marzo de 2001. Asunto C-215/99. Friedrich Jauch vs. Pensionsversicherungsanstalt der Arbeiter [Consulta: 31 de enero de 2017], disponible en <curia.europa.eu/juris/ showPdf.jsf?text $=\&$ docid $=45872$ \&pageIndex $=0 \&$ doclang $=E S \&$ mode $=1$ st $\&$ dir $=\&$ occ $=\mathrm{fi}$ rst\&part=1\&cid=676821>. Sentencia de 31 de mayo de 2001. Asunto C-43/99, Ghislain Leclere \& Alina Deaconescu vs. Caisse nationale des prestations familiales. [Consulta: 31 
Por su parte, en estricto apego y respeto a los principios de proporcionalidad y subsidiariedad, la Comunidad debe complementar la acción de los Estados miembros en materia de seguridad social y protección social de los trabajadores.

e. Colaboración administrativa. Este postulado que adquiere relevancia con la introducción del principio de buena administración por parte del Reglamento 883/2004 se erige como un pilar fundamental para lograr la eficacia de las normas comunitarias en materia de coordinación de los sistemas nacionales de seguridad social, debido a que no sólo implica la ayuda y la cooperación en materia financiera y técnica, sino involucra el intercambio de información entre las autoridades e instituciones y las personas.

Hasta antes del $1^{\circ}$ de mayo de 2010 los instrumentos que servían para el intercambio de información entre los disimiles sistemas de seguridad social nacionales eran los denominados formularios europeos, debido a que en ellos se plasmaba toda la información necesaria para determinar y justificar el derecho a las prestaciones de seguridad social.

A partir del Reglamento 883/2004 opera la Red de Intercambio Electrónico de Información en materia de seguridad social (EESSI) que aunada a los formularios electrónicos estructurados, llamados SED (Structured Electronic Document) ${ }^{40}$ y a los documentos portátiles (Portable Document) ${ }^{41}$ son las herramientas que facilitan el cumplimiento del principio de colaboración.

de enero de 2017], disponible en <http://eur-lex.europa.eu/legal-content/ES/TXT/ PDF/?uri= CELEX:61999CJ0043\& from $=\mathrm{EN}>$.

${ }^{40}$ Los documentos electrónicos estructurados están concebidos para facilitar la comunicación de datos entre instituciones y hacerla más eficaz

${ }^{41}$ Los documentos portátiles sustituyen a los antiguos formularios de la serie E. Los expiden los organismos competentes de seguridad social del país donde usted esté asegurado. Los documentos portátiles son el formulario A1 (antiguos formularios E101 y E103) se utiliza para certificar la legislación aplicable y sirve para acreditar el pago de cotizaciones en otro país miembro de la UE, Islandia, Liechtenstein, Noruega o Suiza. El formulario S1 -que sustituyó a los formularios E106, E109, E120 y E121- se emplea para puede darse de alta para recibir asistencia sanitaria si vive en un país miembro de la UE, Islandia, Liechtenstein, Noruega o Suiza, pero está asegurado en otro de esos países. El formulario S2 -que sustituyó al formulario E112- se emplea para acreditar el derecho a recibir tratamiento médico planificado en otro país miembro de la UE, Islandia, Liechtenstein, Noruega o Suiza. En el caso del trabajador transfronterizo, el formulario S3 le permite recibir tratamiento médico en su antiguo país de trabajo. El formulario DA1 -que corresponde al formulario E123- ampara el derecho a cobertura sanitaria conforme al seguro de accidentes de trabajo y enfermedades profesionales. El formulario U1 (antiguo formulario E301) certifica los periodos cotizados en otro país miembro de la UE, Islandia, Liechtenstein, Noruega o Suiza que se tendrán en cuenta para el cálculo de las prestaciones por desempleo. El formulario U2 (antiguo formulario E303) es la autorización que permite exportar 
$Y$ es que gracias al intercambio informático se agiliza la toma de decisiones en lo referente a la cuantificación y pago de las prestaciones de seguridad social; además de hacer más eficaz tanto la comprobación como la recopilación de datos.

Por supuesto que un factor importante en el cumplimiento de este principio será el papel que desempeñen las instituciones. Específicamente la Comisión Administrativa -cuya composición y funcionamiento se establecen en los artículos 71 y 72 del Reglamento 883/2004- está facultada para resolver cuestiones administrativas, pronunciarse sobre la interpretación de la normativa en materia de coordinación de la seguridad social ${ }^{42}$ y propiciar la colaboración entre los países miembros de la $\mathrm{UE}^{43}$.

las prestaciones por desempleo. El formulario U3 es una notificación enviada por el organismo del país en el que está buscando trabajo. Con ella le comunica que ha informado al organismo del país que paga sus prestaciones por desempleo de los cambios en su situación que pueden justificar una reducción o interrupción de las mismas. El formulario P1 (antiguos formularios E205, E207 y E211) recoge información relativa a las decisiones tomadas por cada país en materia de pensiones. La tarjeta sanitaria europea que permite acceder a la atención sanitaria pública — necesaria por motivos médicos - durante una estancia temporal en cualquiera de los Estados miembros de la UE, además de Islandia, Liechtenstein, Noruega y Suiza.

${ }^{42}$ Constituyen ejemplos de la facultad de interpretación de la normativa en materia de coordinación de la seguridad social con la que cuenta la Comisión Administrativa, los siguientes instrumentos: Decisión n. ${ }^{\circ}$ A1, de 12 de junio de 2009, relativa al establecimiento de un procedimiento de diálogo y conciliación sobre la validez de los documentos, la determinación de la legislación aplicable y el abono de prestaciones de acuerdo con el Reglamento 883/2004; la Decisión número E1, de 12 de junio de 2009, relativas a las disposiciones prácticas en relación con el período transitorio para el intercambio electrónico de datos contemplado en el artículo 4 del Reglamento 987/2009; Decisión número F1, de 12 de junio de 2009, relativa a la interpretación del artículo 68 del Reglamento $883 / 2004$, sobre las normas de prioridad en caso de acumulación de prestaciones familiares; Decisión número H1, de 12 de junio de 2009, relativa al marco para la transición de los Reglamentos $1408 / 71$ y $574 / 72$ a los Reglamentos $883 / 2004$ y 987/2009 y a la aplicación de las Decisiones y Recomendaciones de la Comisión Administrativa de Coordinación de los Sistemas de Seguridad Social; Decisión número P1, de 12 de junio de 2009, relativo a la interpretación del artículo 50, apartado 4, el artículo 58 y el artículo 87, apartado 5, del Reglamento $883 / 2004$, por lo que se refiere a la concesión de prestaciones de invalidez, vejez y supervivencia; Decisión número S1, de 12 de junio de 2009, relativa a la tarjeta sanitaria; Decisión número S2, de 12 de junio de 2009, relativa a las características técnicas de la tarjeta sanitaria; Decisión número S3, de 12 de junio de 2009, por la que se definen las prestaciones contempladas en el artículo 19, apartado 1, y en el artículo 27, aparado 1, del Reglamento 883/2004, así como el artículo 25, sección A, apartado 3 del Reglamento 987/2009.

${ }^{43}$ La Comisión Administrativa cuenta con el apoyo de los siguientes órganos: Comisión Técnica y Comisión de Cuentas. El primer órgano se ocupa del tratamiento de datos con fines de intercambio de información. Por su parte, la Comisión de Cuentas tiene a su 
Por su parte, de conformidad con el artículo 153.2 del TFUE, el Parlamento Europeo y el Consejo tendrán a su cargo la adopción de medidas destinadas a fomentar la cooperación entre los Estados miembros mediante iniciativas para mejorar los conocimientos, desarrollar el intercambio de información y de buenas prácticas, promover fórmulas innovadoras y evaluar experiencias, con exclusión de toda armonización de las disposiciones legales y reglamentarias de los Estados miembros.

En tanto que la Comisión Europea tiene el deber de examinar la legislación y vigilar la aplicación y coordinación de los sistemas de seguridad social para salvaguardar los derechos a prestaciones de los trabajadores migrantes de la $\mathrm{UE}^{44}$.

e. Totalización. Por disposición de este principio, en aras de facilitar la libre circulación de los trabajadores, al evaluar la cobertura del período de cotización para acceder a las prestaciones de carácter contributivo y no contributivo previstas en los reglamentos comunitarios, así como para el cálculo de éstas, se deben contabilizar todos los períodos de seguro, empleo o residencia cumplidos en cualquier otro Estado miembro de la Unión Europea, en aquellos Estados Parte del Espacio Económico Europeo o en Suiza ${ }^{45}$.

Actualmente con arreglo al procedimiento legislativo ordinario instituido por el Tratado de Lisboa; el Parlamento Europeo y el Consejo adoptarán en materia de seguridad social las medidas necesarias, para que de ejercerse el derecho fundamental de libre circulación de los trabajadores, con base en el principio de totalización se tomen en consideración todos los períodos reconocidos por las distintas legislaciones nacionales para adquirir y conservar el derecho a las prestaciones sociales ${ }^{46}$.

Con excepción de las prestaciones de prejubilación, cabe mencionar que por disposición del Reglamento 883/2004 se establece la obligación de totalizar los periodos de seguro en los diferentes Estados miembros en lo que concierne a las prestaciones de invalidez, vejez, enfermedad, defunción y las

cargo la comprobación del método de determinación y de cálculo de los costes medios anuales presentados por los Estados miembros; la reunión de los datos pertinentes y proceder a los cálculos necesarios para determinar el estado anual de los créditos correspondientes a cada Estado miembro; así como la realización de todos los trabajos, estudios o misiones sobre los asuntos que le remita la Comisión Administrativa.

${ }^{44}$ Resolución de 14 de enero de 2014, sobre la protección social para todos, incluidos los trabajadores autónomos

45 En los artículos 69.4 del Tratado del Carbón y e1 Acero, el artículo 51 del Tratado de Maastricht y el artículo 42 del Tratado de Ámsterdam se encuentra plasmado el principio de totalización.

46 Artículo 48 del TFUE [Consulta: 24 de enero de 2017], disponible en $<$ https:// www.boe.es//doue/2010/083/Z00047-00199.pdf> 
familiares. Las reglas de la totalización se encuentran consignadas en el artículo 6 del Reglamento 883/2004, en los términos siguientes:

Salvo disposición en contrario del presente Reglamento, la institución competente de un Estado miembro cuya legislación subordine:

- la adquisición, la conservación, la duración o la recuperación del derecho a las prestaciones,

- la admisión a una legislación, o

- el acceso o la exención del seguro obligatorio, voluntario o facultativo continuado,

al requisito de haber cubierto períodos de seguro, de empleo, de actividad por cuenta propia o de residencia, tendrá en cuenta, en la medida necesaria, los períodos de seguro, de empleo, de actividad por cuenta propia o de residencia cubiertos bajo la legislación de cualquier otro Estado miembro, como si se tratara de períodos cubiertos bajo la legislación que dicha institución aplica.

f. Exportabilidad. Este principio se traduce en la prohibición de reducción, suspensión, modificación, supresión o confiscación de una prestación económica de seguridad social por el mero hecho de que la persona beneficiaria haya fijado su residencia en un Estado miembro distinto del que radica la institución deudora ${ }^{47}$.

Y es que, si bien por disposición del artículo 7 del Reglamento 883/2004 ${ }^{48}$ se suprime la regla desterritorializadora -conforme a la cual se prohíbe que los Estados miembros reserven el pago de prestaciones a las personas que residan en ellos-, el principio de exportabilidad no aplica a todas las prestaciones sociales.

El Reglamento 883/2004 contiene disposiciones que establecen que las prestaciones de vejez, enfermedad, invalidez, defunción y las familiares deben seguir siendo abonadas a sus perceptores residentes en otro Estado miembro o a los que regresen a su país de origen.

Empero, en ningún caso son exportables las prestaciones no contributivas en metálico que contengan elementos tanto de asistencia social como de

${ }^{47}$ Cristina Sánchez-Rodas Navarro, Sinopsis del Reglamento, op. cit., nota 17, p. 185.

48 Artículo 7 del Reglamento (CE) n. ${ }^{\circ}$ 883/2004: Supresión de las cláusulas de residencia: Salvo disposición en contrario del presente Reglamento, las prestaciones en metálico debidas en virtud de la legislación de uno o de varios Estados miembros o del presente Reglamento no podrán sufrir ninguna reducción, modificación, suspensión, supresión o confiscación por el hecho de que el beneficiario o los miembros de su familia residan en un Estado miembro distinto de aquel en que se encuentra la institución deudora. [Consulta: 3 de febrero de 2017], disponible en <eur-lex.europa.eu/LexUriServ.do?uri= OJ:L:2004:166:0001:0123:es:PDF> 
prestaciones de seguridad social, así como tampoco está previsto indexar las prestaciones por hijos a cargo, y por tanto, el país en el que trabajan los padres permanece como responsable del pago de dichas prestaciones, y su importe no se puede ajustar al país de residencia del menor ${ }^{49}$.

En el caso del subsidio por desempleo sólo puede exportarse durante un máximo de tres meses, pero existe la posibilidad de extender este período hasta un máximo de seis meses ${ }^{50}$. Asimismo, se garantiza el derecho de los inmigrantes a percibir las prestaciones de prejubilación en las mismas condiciones que los nacionales y a que éstas puedan exportarse si se trasladan al extranjero después de jubilarse.

g. Conservación de derechos adquiridos y en curso de adquisición. En virtud de este principio, el trabajador desplazado a otros Estados miembros debe conservar los derechos que hubiese consolidado en uno de los Estados miembro. Estos derechos en ningún caso deben verse mermados como consecuencia de la libre circulación de trabajador.

h. De asimilación. Recogido en el Considerando 10 y en el artículo 5 del Reglamento 883/2004, este principio consiste en tratar determinados hechos o acontecimientos ocurridos en el territorio de otro Estado miembro como si hubieran ocurrido en el territorio del Estado miembro cuya legislación sea aplicable.

\section{NORMATIVA DE LA UNIÓN EUROPEA EN MATERIA DE SEGURIDAD SOCIAL.}

La adopción de las decisiones y normatividad en el ámbito de la seguridad social ha estado sujeta a diversos procedimientos entre los que destacan la codecisión introducida en el Tratado de Maastricht ${ }^{51}$, pasando en los Tratados de Ámsterdam ${ }^{52}$ y Niza ${ }^{53}$ por la decisión del Consejo por

${ }^{49}$ En la Unión, menos del 1\% de las prestaciones por hijos a cargo se exportan de un Estado miembro a otro.

${ }^{50}$ Artículo 64.3 del Reglamento (CE) n. ${ }^{\circ} 883 / 2004$ [Consulta: 3 de febrero de 2017], disponibleen<eur-lex.europa.eu/LexUriServ.do?uri=OJ:L:2004:166:0001:0123:es:PDF>

51 Artículo 51 del Tratado de Maastricht [Consulta: 13 de enero de 2017], disponible en $<$ http://www.pnsd.msssi.gob.es/pnsd/legislacion/pdfestatal/i77.pdf $>$

52 Artículo 118 del Tratado de Ámsterdam [Consulta: 26 de enero de 2017], disponible en $<$ https://europa.eu/european-union/sites/europaeu/files/docs/body/treaty_of_amsterdam_es.pdf $>$

53 Artículo 137 del Tratado de Niza [Consulta: 13 de enero de 2017], disponible en $<$ https://www.ecb.europa.eu/ecb/legal/pdf/es_nice.pdf $>$ 
unanimidad, a propuesta de la Comisión, previa consulta al Parlamento Europeo, al Comité Económico y Social así como al Comité de las Regiones.

Será con la entrada en vigor del Tratado de $\operatorname{Lisboa}^{54}$ que se instaura el procedimiento legislativo ordinario ${ }^{55}$ y los procedimientos especiales ${ }^{56}$ como medios para la producción de las normas de la UE en el ámbito de la seguridad social.

El artículo 153 del TFUE (antiguo artículo 137 del TCE) ${ }^{57}$ introduce una cláusula pasarela para la aplicación del procedimiento legislativo ordinario en lo referente a la protección de los trabajadores en caso de rescisión del contrato laboral; la representación y la defensa colectiva de los intereses de los trabajadores y de los empresarios, incluida la cogestión, sin perjuicio de lo dispuesto en el apartado 5 del mismo numeral; además de las condiciones de empleo de los nacionales de terceros países que residan legalmente en el territorio de la Comunidad ${ }^{58}$. Empero al ámbito de la seguridad social no resulta aplicable la referida pasarela.

Un aspecto ha destacar con la entrada en vigor del Tratado de Lisboa es la introducción de las denominadas cláusulas de freno. La aplicación de este tipo de cláusulas posibilitan la suspensión del procedimiento legislativo ordinario en caso de que un país considere que los principios fundamentales, coste o estructura financiera de su sistema de seguridad social se encuentran amenazados por la legislación en proceso de adopción.

En tales circunstancias, el procedimiento se suspende y se reenvía el proyecto al Consejo Europeo.. Previa deliberación y en un plazo de cuatro

${ }^{54}$ Después de ser ratificado por los 27 Estados miembros de la Unión Europea, el Tratado de Lisboa entró en vigor el $1^{\circ}$ de diciembre de 2009

${ }^{55}$ Las modalidades del procedimiento legislativo ordinario -detalladas en el artículo 294 del Tratado de Funcionamiento de la Unión Europea- son idénticas a las del antiguo procedimiento de codecisión.. En el procedimiento ordinario el Consejo y el Parlamento adoptan los actos legislativos en primera lectura o en segunda lectura. Si al finalizar la segunda lectura, las dos instituciones aún no han llegado a un acuerdo, se convoca un Comité de Conciliación

${ }^{56}$ Los procedimientos legislativos especiales sustituyen a los antiguos procedimientos de consulta, de cooperación y de dictamen conforme.

${ }^{57}$ En el artículo 137 del Tratado de Niza introducía una cláusula pasarela para la aplicación del procedimiento de codecisión en lo referente a la protección de los trabajadores en caso de rescisión del contrato laboral; la representación y la defensa colectiva de los intereses de los trabajadores y de los empresarios, incluida la cogestión, sin perjuicio de lo dispuesto en el apartado 5 del mismo numeral; además de las condiciones de empleo de los nacionales de terceros países que residan legalmente en el territorio de la Comunidad

${ }^{58}$ La activación de las cláusulas pasarelas generales debe ser autorizada por una decisión del Consejo Europeo por unanimidad 
meses a partir de la suspensión, el Consejo Europeo podrá devolver el proyecto al Consejo de la UE, quien continuará con el procedimiento legislativo teniendo en cuenta las observaciones formuladas. Aunque también el Consejo Europeo puede poner fin al procedimiento legislativo y solicitar, si procede, una nueva iniciativa de ley por parte de la Comisión Europea $^{59}$.

Ahora bien como indica su denominación, los procedimientos especiales son derogatorios al procedimiento legislativo ordinario y, por tanto, constituyen excepciones. Su objetivo es simplificar el proceso de toma de decisiones de la UE, debido a que Consejo es el único legislador, quedando el Parlamento Europeo, el Comité Económico y Social así como el Comité de las Regiones asociados al procedimiento para la consulta o la aprobación dependiendo de la naturaleza de los casos.

Es así que de cualesquiera procedimientos de legislación comunitaria emana el Derecho de la UE. Dentro del sistema de la Unión Europea, los tratados fundacionales, modificativos, de adhesión y los complementarios al conformar el Derecho primario constituyen las reglas fundamentales de toda la actuación de la UE.

Por su parte, el Derecho derivado comprende los actos unilaterales y los actos convencionales. El primer tipo de actos distingue entre las disposiciones que figuran en el artículo 288 del TFUE y aquellas que no se encuentran previstos en este numeral. A diferencia de las comunicaciones, las recomendaciones, los libros blancos y verdes que se constituyen como actos atípicos; el reglamento, la directiva, la decisión, el dictamen y la recomendación forman parte de la primera categoría de actos unilaterales

En cuanto a los actos convencionales tenemos que éstos no derivan de un procedimiento legislativo. Se trata de acuerdos concertados entre los Estados miembros, acuerdos internacionales firmados entre la UE, por una parte, y un tercer país u organización por otra, además de los acuerdos interinstitucionales, es decir, aquellos celebrados entre las instituciones de la UE.

Finalmente, como fuentes subsidiarias de la UE se encuentran la jurisprudencia del Tribunal de Justicia, el Derecho internacional y los principios generales del Derecho.

Normalmente los reglamentos emanados de las instituciones de la UE -pero fortalecidos con la jurisprudencia del Tribunal de Luxemburgoconstituyen, por su naturaleza vinculante y eficacia (alcance general, obligatoriedad en todos sus elementos y aplicación directa en cada uno de los Estados miembros), el típico instrumento de unificación normativa o, lo

59 Artículo 48 del TFUE [Consulta: 24 de enero de 2017], disponible en $<$ https:// www.boe.es//doue/2010/083/Z00047-00199.pdf> 
que es igual, de imposición a los Estados de un derecho único ${ }^{60}$. Además de que al prevalecer el reglamento sobre los ordenamientos jurídicos de cada Estado miembro ${ }^{61}$, (primacía normativa) su acatamiento es inmediato por todas las autoridades nacionales, sin que sea necesaria su incorporación previa a los sistemas jurídicos nacionales.

El objetivo de los reglamentos, como instrumentos de coordinación, no sólo es evitar que los trabajadores migrantes pierdan sus derechos de seguridad social al ejercitar la libertad fundamental a la libre circulación, sino también evadir una doble cobertura en situaciones transfronterizas.

Bajo esta luz, el primer instrumento en materia de coordinación de la seguridad social en Europa fue el Reglamento número 3, de 25 de septiembre de 1958, relativo a la seguridad social de migrantes; cuyo instrumento de aplicación era el Reglamento número 4, de 3 de diciembre de 1959. Ambos reglamentos correspondientes a la Comunidad Europea del Acero y el Carbón (CECA) -vigentes a partir del $1^{\circ}$ de enero de 1959- tenían como objetivo garantizar la protección social de los trabajadores del carbón y del acero que se desplazaban a otros países.

A este tipo de disposiciones siguieron los Reglamentos de Coordinación números 474/72 y 1408/71 del Consejo, de 14 de junio de 1971 relativo a la aplicación de los regímenes de seguridad social a los trabajadores por cuenta ajena y a sus familias que se desplazan dentro de la Comunidad, de cuyas modalidades de aplicación se ocuparía el Reglamento número 574/72, de 21 de marzo de $1972^{62}$.

La creciente complejidad de los reglamentos $1408 / 71$ y 574/72 derivada de las múltiples modificaciones realizadas a ambas disposiciones ${ }^{63}$ impulsa-

${ }^{60}$ Javier Gárate Castro, op. cit., nota 14, p. 25.

${ }^{61}$ El Tribunal de Justicia de la CE en su sentencia del Asunto C-118/00, Larsy determinó que si las normas procesales nacionales se oponían a la protección efectiva de los derechos que se derivaban del efecto directo del Derecho comunitario, la administración nacional debería haber excluido su aplicación. [Consulta: 2 de febrero de 2017], disponible en $<$ http://curia.europa.eu/juris/showPdf.jsf?text $=\&$ docid $=46474 \&$ pageIndex $=0 \&$ doc lang $=$ ES\&mode $=1$ st\&dir $=\&$ occ $=$ first \&part $=1 \&$ cid $=571430>$

${ }_{62}$ Los Reglamentos 1408/71 y 574/72 entraron en vigor el 1 de octubre de 1972, sustituyendo a los Reglamentos 3 y 4.

${ }_{63}$ El Reglamento $3795 / 81$ ha extendido a los trabajadores por cuenta propia y a los miembros de sus familias el Reglamento 1408/71. Modificaciones realizadas al Reglamento 1408/71: Reglamento 1390/81, del Consejo, de 12 de mayo de 1981; Reglamento 2793/81, de 17 de septiembre 1981; Reglamento 2001/83, del Consejo, de 2 de junio de 1983; Reglamento 1247/92, Consejo de 30 de abril de 1992; Reglamento 3095/95, del Consejo, de 22 de diciembre de 1995; Reglamento 1290/97, del Consejo, de 27 de junio de 1997; Reglamento 118/97, del Consejo, de 2 de diciembre 1996; Reglamento 1223/98, del Consejo, de 4 de junio de 1998; Reglamento 1606/98, del Consejo, de 29 de junio de 1998; Reglamento 307/1999, del Consejo, de 8 de fe- 
das en su mayoría por la abundante jurisprudencia del Tribunal de Justicia de la Unión Europea, la adhesión de nuevos Estados al sistema de coordinación, la evolución de las legislaciones nacionales de seguridad social aunadas a la necesidad de reforzar la cooperación administrativa entre los Estados con la finalidad de hacer posible y efectiva la libertad de circulación en la UE, fueron los motores que impulsaron la revisión, simplificación y modernización

brero de 1999; Reglamento 1399/1999 del Consejo, de 29 de abril de 2009; Reglamento $1386 / 2001$, del Parlamento Europeo y del Consejo, de 5 de junio de 2001; Reglamento 859/03, del Consejo, de 14 de mayo 2003; el Acta relativa a las condiciones de adhesión de la República Checa, la República de Estonia, la República de Chipre, la República de Letonia, la República de Lituania, la República de Hungría, la República de Malta, la República de Polonia, la República de Eslovenia y la República Eslovaca, y a las adaptaciones de los Tratados en los que se fundamenta la Unión; Reglamento 631/2004, del Parlamento Europeo y el Consejo, de 31 de marzo de 2004; Reglamento $647 / 2005$, del Parlamento y del Consejo, de 13 de abril de 2005; Reglamento 629/2006, del Parlamento y del Consejo, de 5 de abril de 2006; Reglamento 1791/2006, del Consejo, de 20 de noviembre de 2006; Reglamento 1992/2006 del Parlamento y del Consejo, de 18 de diciembre de 2006 y Reglamento 592/2008, del Parlamento y del Consejo, de 17 de junio de 2008. Modificaciones realizadas al Reglamento 574/72: Reglamento 2864/72, del Consejo, de 19 de diciembre de 1972; Reglamento 1392/74, del Consejo, de 4 de junio de 1974; Reglamento 1209/76, del Consejo, de 30 de abril de 1976; Reglamento 2595/77, de 21 de noviembre de 1977; Reglamento 1390/81, del Consejo, de 12 de mayo de 1981; Reglamento 2793/81; Reglamento 2474(82, de $1^{\text {o }}$ de septiembre de 1982; Reglamento 799/83; Reglamento 2001/83, del Consejo, de 2 de junio de 1983; Reglamento 1660/85, del Consejo, de 13 de junio de 1985; Reglamento 1305/89, del Consejo, 11 de mayo de 1989; Reglamento 2332/89, del Consejo, de 18 de julio de 1989; Reglamento 3427/89, del Consejo, de 30 de octubre de 1989; Reglamento 2195/91, del Consejo, de 25 de junio de 1991; Reglamento 1247/92, del Consejo, de 30 de abril de 1992; Reglamento 1945/93, del Consejo, de 30 de junio de 1993; Reglamento 3095/95, del Consejo, de 22 de diciembre de 1995; Reglamento 1290/97, del Consejo, de 27 de junio de 1997; Reglamento 1223/98, del Consejo, de 4 de junio de 1998 y Reglamento 1606/98, del Consejo, de 29 de junio de 1998; Reglamento 307/1999, del Consejo de 8 de febrero de 1999; Reglamento 1399/1999, del Consejo, de 29 de abril de 1999; Reglamento 89/2001, de la Comisión, de 17 de enero de 2001; Reglamento 1386/2001, del Parlamento Europeo y Consejo, de 5 de mayo de 2001; Reglamento 410/2002, de la Comisión, de 27 de febrero de 2002; Reglamento 859/2003, del Consejo, de 14 de mayo de 2003; Reglamento 1851/2003, de la Comisión, de 17 de octubre de 2003; Reglamento 631/2004, del Parlamento Europeo y el Consejo, de 31 de marzo de 2004; Reglamento 77/2005, de la Comisión, de 13 de enero de 2005; Reglamento 647/2005, del Parlamento Europeo y del Consejo, de 13 de abril de 2005; Reglamento 207/2006, de la Comisión, de 7 de febrero de 2006; Reglamento 629/2006, del Parlamento Europeo y Consejo, de 5 de abril de 2006; Reglamento 1791/2006, del Consejo, de 20 de noviembre de 2016; Reglamento 311/2006, de la Comisión, de 19 de marzo de 2007; Reglamento 101/2008, de la Comisión, de 4 de febrero de 2008 y Reglamento 120/2009, de la Comisión, de 9 de febrero de 2009. 
de las normas de coordinación de los sistemas de seguridad social de los Estados miembros ${ }^{64}$.

Por consiguiente, a partir del $1^{\circ}$ de mayo de 2010 opera la sustitución de los Reglamentos $1408 / 71$ y $574 / 72^{65}$ por el Reglamento de base número 883/2004 del Parlamento Europeo y del Consejo, de 29 de abril de 2004, sobre la coordinación de los sistemas de seguridad social (DO L 200, 7.6.2004) y por el correspondiente Reglamento n. ${ }^{\circ}$ 987/2009 del Parlamento Europeo y del Consejo, de 16 de septiembre de 2009, por el que se adoptan las normas de aplicación del Reglamento 883/2004, sobre la coordinación de los sistemas de seguridad social (DO L 284 de 30.10.2009).

Al igual que las anteriores disposiciones, los Reglamentos (CE) n. ${ }^{\circ} 883 / 2004$ $\mathrm{y} \mathrm{n.}^{\circ}$ 987/2009 no reemplazan la legislación nacional, sino que se ocupan de coordinar los diferentes sistemas nacionales de seguridad social a fin de que cualquier persona que desee ejercer su derecho a la libre circulación y su derecho de residencia no sea discriminada con respecto a las personas que hayan estado residenciadas y hayan trabajado siempre en el mismo país.

Conforme al artículo 2 del Reglamento 883/2004, el ámbito de aplicación personal se circunscribe a los nacionales de un Estado miembro de la Unión

${ }^{64}$ La necesidad de una revisión general al Reglamento 1408/71 se reconoció en el Consejo de Edimburgo de 1992, en el que se preconizó una simplificación de las normas. Además, la Comisión confirmó la importancia de modernizar las normas de coordinación en la Comunicación de 1997 intitulada Plan de acción para la libre circulación de los trabajadores.

${ }^{65}$ Por disposición del artículo 90 del Reglamento n. ${ }^{\circ} 883 / 2004$ y el artículo 96 del Reglamento n. ${ }^{\circ}$ 987/2009, se determinó que los Reglamentos (CEE) n. ${ }^{\circ} 1408 / 71$ y n. ${ }^{\circ}$ $574 / 72$ seguirán en vigor y se mantendrán sus efectos jurídicos en lo relativo a los siguientes efectos:

a. El Reglamento (CE) 859/2003, del Consejo, de 14 de mayo de 2003, destinado a los nacionales de terceros países que, debido únicamente a su nacionalidad, no estén cubiertos por estas disposiciones

b El Reglamento (CEE) 1661/85, de 13 de junio de 1985, por el que se establecen las adaptaciones técnicas de la normativa comunitaria en materia de Seguridad Social de los trabajadores migrantes en lo que se refiere a Groenlandia.

c. El Acuerdo sobre el Espacio Económico Europeo, al Acuerdo entre la Comunidad Europea y sus Estados miembros por un lado, y la Confederación Suiza por otro, sobre la libre circulación de personas; y otros acuerdos que hacen referencia al Reglamento (CEE) 1408/71. Reglamento 883/2004 [Consulta: 13 de enero de 2017], disponible en <eur-lex. europa.eu/LexUriServ.do?uri=OJ:L:2004:166:0001:0123:es:PDF>. Reglamento 987/2009, [Consulta: 11 de enero de 2017], disponible en <http://eur-lex.europa.eu/LexUriServ/LexUriServ.do?uri=OJ:L:2009:284:0001:0042:es:PDF>

2. La Directiva 98/49/CE, del Consejo, de 29 de junio de 1998, relativa a la protección de los derechos de pensión complementaria de los trabajadores por cuenta ajena y los trabajadores por cuenta propia que se desplazan dentro de la Comunidad. 
Europea $^{66}$, de Islandia, Noruega, Liechtenstein, Suiza ${ }^{67}$, de un Estado parte del Espacio Económico Europeo ${ }^{68}$, a los apátridas o refugiados residentes en uno de los Estados miembros de la Unión Europea, en un Estado parte del Espacio Económico Europeo o Suiza, así como a los miembros de sus familias y los supérstites.

Igualmente, el Reglamento 883/2004 resulta aplicable a los supérstites de personas que hayan estado sujetas a la legislación de uno o varios Estados miembros, cualquiera que sea la nacionalidad de éstas, si dichos supervivientes son nacionales de un Estado miembro de la Unión Europea, de un Estado Parte del Espacio Económico Europeo, de Suiza, así como a los refugiados o apátridas residentes en el territorio de la Unión Europea, del Espacio Económico Europeo, o de Suiza.

Es necesario mencionar que en virtud del Reglamento (CE) número $1231 / 2010^{69}$, a los nacionales de terceros países y a sus familiares, también les resultan aplicables los Reglamentos 883/2004 y 987/2009, pero deberán acreditar la legalidad de la residencia en un Estado miembro de la Unión.

Por su parte, el campo de aplicación material del Reglamento 883/2004 se amplía a la protección de las siguientes contingencias ${ }^{70:}$

- Prestaciones de enfermedad (asistencia sanitaria e incapacidad temporal)

- Prestaciones de maternidad y de paternidad asimiladas

- Prestaciones de accidentes de trabajo y de enfermedades profesionales

- Prestaciones de invalidez

- Pensiones de vejez (jubilación)

- Prestaciones de supervivencia

- Subsidios de defunción

${ }^{66}$ La Unión Europea nace en el Tratado de Maastricht y se integra por Alemania, Austria, Bélgica, Bulgaria, Chipre, Dinamarca, Eslovaquia, Eslovenia, España, Estonia, Finlandia, Francia, Grecia, Hungría, Irlanda, Italia, Letonia, Lituania, Luxemburgo, Malta, Países Bajos, Polonia, Portugal, República Checa, Rumanía y Suecia. Desde $1^{\circ}$ de mayo de 2010 el Reglamento 883/2004 resulta aplicable a los trabajadores nacionales de la Unión Europea que se desplacen a los países de la Unión Europea. El Reglamento $883 / 2004$ es aplicable a partir del $1^{\circ}$ de julio de 2013 a los trabajadores, cualquiera que sea su nacionalidad, que se desplacen a Croacia.

${ }^{67}$ Desde $1^{\circ}$ de abril de 2012 Reglamento 883/2004 resulta aplicable a los trabajadores de la Unión Europea y suizos que se desplacen a Suiza.

${ }^{68}$ Son países pertenecientes al Espacio Económico Europeo: Islandia, Liechtenstein y Noruega. A partir del 1 de junio de 2012 el Reglamento 883/2004 es aplicable a los trabajadores nacionales la Unión Europea y del Espacio Económico Europeo.

69 En Dinamarca los Reglamentos Comunitarios de Seguridad Social no son aplicables a los nacionales de terceros países.

70 Artículo 3 del Reglamento 883/2004 [Consulta: 3 de febrero de 2017], disponible en <eur-lex.europa.eu/LexUriServ.do?uri= OJ:L:2004:166:0001:0123:es:PDF> 
- Prestaciones de desempleo

- Prestaciones familiares ${ }^{71}$

- Prestaciones de prejubilación

- Prestaciones especiales en metálico no contributivas

- Regímenes de seguridad social generales y especiales, contributivos y no contributivos, así como a los regímenes relativos a las obligaciones del empleador o del armador.

Como consecuencia de lo anterior, tenemos que el Reglamento 883/2004 se decanta por el mantenimiento del sistema de lista cerrada de prestaciones contributivas como no contributivas de seguridad social, y a pesar de que amplia su campo de aplicación material en favor de los derechohabientes al extender su cobertura a los regímenes legales de prejubilación, no cubre la asistencia social ${ }^{72}$ y médica, ni tampoco los regímenes de prestaciones en favor de las víctimas de guerra o de sus consecuencias.

$\mathrm{Y}$ es que ante la inexistencia de una legislación única en materia de seguridad social que sea aplicable a todos los ciudadanos de los diversos Estados miembros, los reglamentos 883/2004 y 987/2009 - cada vez con mayor dificultad- al coordinar la aplicación de las diversas normativas de seguridad social de los respectivos Estados no sólo prescriben la aplicabilidad del sistema de seguridad social en los casos de desplazamiento en la UE, sino también decretan la procedencia, determinación y cálculo de las prestaciones, así como los requisitos para acceder a las mismas y demás particularidades del régimen de seguridad social establecidas por cada Estado miembro a través de su legislación.

Así, resulta claro que dentro de la UE, impera la disparidad y tipología de las prestaciones que integran las ramas del sistema de seguridad social existentes en las legislaciones nacionales coordinadas por los aludidos reglamentos.

\section{REGLAMENTOS DE COORDINACIÓN VS. CONVENIOS BILATERALES.}

El artículo 6 del Reglamento 1408/71 establecía la sustitución de todos los convenios de seguridad social que vincularan a dos o más Estados miembros. Este precepto fue reproducido literalmente en la sentencia pronunciada el $7 \mathrm{de}$

${ }^{71}$ El Reglamento 1408/71 distinguía entre prestaciones familiares y subsidios familiares. el Reglamento 883/2004 suprime tal dualidad optando por el término prestaciones familiares

${ }^{72}$ Las prestaciones de asistencia social están destinadas a combatir la pobreza y se conceden normalmente sobre la base de una evaluación individual de las necesidades y circunstancias de la persona que las solicita. 
junio de 1973 por el antiguo Tribunal de Justicia de la Comunidad Europea con motivo del caso Walder ${ }^{73}$.

Es así que la tesis de la derogación de los Convenios bilaterales sustentada en la imperatividad absoluta del Reglamento 1408/71 fue la que prevaleció hasta que el 7 de febrero de 1991 con motivo del asunto Rönfeldt, el Tribunal de Justicia de la Unión Europea determinó la no sustitución de los Convenios Bilaterales precedentes a la integración, cuando éstos son más favorables para los trabajadores que la normativa comunitaria ${ }^{74}$

De igual forma, las sentencias dictadas en los asuntos Thelen ${ }^{75}$, Naranjo, ${ }^{76}$ Arjona $^{77}$, Thévenon ${ }^{78}$ y Grajera ${ }^{79}$ reiteran la aplicación más favorable de las

${ }^{73}$ En la sentencia de 7 de junio de 1973, Walder (82/72, Rec. p. 599), apartados 6 y 7, relativa a la interpretación de los artículos 5 y 6 del Reglamento n. ${ }^{\circ} 3$, antes citado, y 6 y 7 del Reglamento n. $^{\circ} 1408 / 71$, el Tribunal de Justicia subrayó que dichas disposiciones ponen claramente de manifiesto que la sustitución de las disposiciones de los Convenios de Seguridad Social celebrados entre Estados miembros por los Reglamentos comunitarios tiene carácter imperativo y no admite excepciones fuera de los casos expresamente mencionados en los Reglamentos, ni siquiera en el supuesto de que dichos Convenios de Seguridad Social impliquen, para las personas a las que se aplican, prestaciones superiores a las que resultan de dichos Reglamentos.

${ }^{74}$ Sentencia del Tribunal de Justicia de la Unión de 7 de febrero de 1991. Asunto C-227/89, Ludwig Rönfeldt y Bundesversicherungsanstalt Für Angestellte [Consulta: 1 de febrero de 2017], disponible en $\mathrm{http} / /$ curia.europa.eu/juris/showPdf.jsfjsessionid=9ea7d0f130d 5b4881931b9c049508d97bb2f7bc97c4f.e34Kax iLc3eQc40LaxqMbN4OchiLe0?text=\&doci $\mathrm{d}=96853$ \&pageIndex $=0$ \&doclang $=\mathrm{ES} \&$ mode $=1$ st\&dir $=\&$ occ $=$ first\&part $=1 \&$ cid $=455045>$

75 Sentencia del Tribunal de Justicia de la Unión de 9 de noviembre de 2000. Asunto C-75/99. Edmund Thelen y Bundesanstalt für Arbeit, [Consulta 1 de febrero de 2017], disponible en $<$ http://curia.europa.eu/juris/showPdfjsf;jsesssionid=9ea7d2dc30d645ebe2 1c5c7748828d43a9f83da66018.e34KaxiLc3qMb40Rch0SaxuOa310?docid=43786\&pag eIndex $=0 \&$ doclang $=E S \&$ mode $=\&$ dir $=\& o c c=$ first $\&$ part $=1 \&$ cid $=192799>$.

76 Sentencia del Tribunal de Justicia de la Unión Europea de 21 de diciembre de 2016. Asunto C154/15, Francisco Gutiérrez Naranjo contra Cajasur Banco SAU [Consulta: 1 de febrero de 2017], disponible en $<$ http://curia.euroa.eu/juris/document/document.jsf?text\&doc id $=186483$ \&pageIndex $=0 \&$ doclang $=$ ES\&mode $=$ req\&dir\&occ $=$ first\&part $=1 \&$ cid $=509967>$

77 Sentencia del Tribunal de Justicia de la Unión de 17 de diciembre de 2015, Asunto C407/14. María Auxiliadora Arjona Camacho y Securitas Seguridad España, S.A. [Consulta 28 de enero de 2017], disponible $<$ http://curia.europa.eu/juris/showPdf.jsf:jsessionid=9ea7d0f130 d63ac7860af8664c8da5bbb57621b5cb19e3 4KaxiLc3eQc40LaxqMbN4OaN8Qe0?text=\&do cid $=43415$ \&pageIndex $=0 \&$ doclang $=E S \&$ mode $=$ req\&dir $=\& o c c=$ first\&part $=1 \& \mathrm{cid}=491415>$

${ }_{78}$ Sentencia del Tribunal de Justicia de la Unión de 9 de noviembre de 1995. Asunto C-475/93. Jean-Louis Thévenon y Stadt Speyer-Sozialamt contra Landesversicherungsanstalt Rheinland-Pfalz. [Consulta 28 de enero de 2017], disponible $<$ http://curia.europa.eu/juris/showPdf.jsf:jsessionid=9ea7d0f130d5a8d1d47a983c46aab48b88adbb a8820c.e34KaxiLc3eQc40LaxqMbN4Pa3uNe0?text $=$ \&docid=99385\&pageIndex $=0$ \&do clang $=$ ES\&mode $=1$ st \&dir $=\&$ occ $=$ first $\&$ part $=1 \&$ cid $=1336562>$

79 Sentencia del Tribunal de Justicia de la Unión de 17 de diciembre de 1998. Asunto C-153/97 Aristóteles Grajera Rodríguez e Instituto Nacional de la Seguridad Social 
disposiciones de un Convenio Bilateral. Siguiendo esta última línea de interpretación del Tribunal de Luxemburgo, el artículo 8 del Reglamento 883/2004 determina la aplicabilidad de los convenios de seguridad social suscritos por los Estados miembros con anterioridad a la fecha de aplicación del Reglamento, siempre que resulten más favorables para los beneficiarios o deriven de circunstancias históricas específicas y tengan un efecto temporal limitado, quedando la aplicabilidad de los convenios supeditada a su inclusión en el Anexo II del Reglamento 883/2004 modificado por el Reglamento 988/2009.

Generalmente los órganos jurisdiccionales, para resolver los conflictos normativos sobre la base de la aplicación del principio de la norma más favorable, han recurrido a los métodos básicos de acumulación o espigueo, inescindibilidad o conglobamiento y inescindibilidad de los institutos o conglobamiento por instituciones.

Mientras la técnica de conglobamiento o globalización implica la aplicación de la norma que en su totalidad resulte más favorable al trabajador; por el contrario el criterio de acumulación o espigueo implica la aplicación de una nueva norma que deriva de haber extraído de las normas concurrentes aquello que resulte más favorable al trabajador (una especie de Frankenstein $^{80}$ o híbrido normativo). El Tribunal de la UE se ha decantado por este segundo método ${ }^{81 .}$

Tratándose del método de la inescindibilidad de los institutos o conglobamiento de las instituciones toma como unidad de comparación el conjunto de normas relacionadas con cada una de las instituciones del derecho laboral, aplicándose la norma que regula de modo más favorable cada una de las instituciones comparadas ${ }^{82}$. Este método intermedio, a pesar de que permite el

(INSS) y Tesorería General de la Seguridad Social (TGSS), [Consulta 26 de enero de 2017], disponible en <http://curia.europa.eu/juris/showPdf.jsf:jsessi

${ }^{\circ}$ nid=9ea7d0f130d63ac7860af8664c8da5bbb57621b5cb19.e34KaxiLc3eQc40Laxq MbN4OaN8Qe0?text $=\&$ docid $=43415 \&$ pageIndex $=0 \&$ doclang $=$ ES\&mode $=$ req \&dir $=\& 0$ $\mathrm{cc}=$ first\&part $=1 \&$ cid $=192799>$

${ }^{80}$ Claudio Palavecino Cáceres, Los principios del derecho del trabajo, [Consulta: 2 de febrero de 2017], disponible en <https://www.u-cursos.cl/derecho/2012/2/D128A0523/2/ material_docente/bajar?>

${ }^{81}$ Del contexto de la sentencia Rönfeldt se infiere, además, que la comparación que procede efectuar entre el Reglamento y el convenio bilateral no es sólo en su conjunto, sino que se refiere a todas y cada una de las reglas de coordinación contenidas en el Reglamento y en el convenio, con el fin de aplicar la que figure en éste cuando resultase más favorable para el trabajador. Emilio González-Sancho López, «Relaciones entre Legislación Comunitaria y Convenios Bilaterales en Materia de Seguridad Social de Migrantes: de la Sentencia Rönfeldt al caso Peschiutta», Revista de Trabajo y Seguridad Social, número 5 (1992), 81-94.

${ }^{82}$ Christian Courtis, El mundo prometido. Escrito sobre derechos sociales y derechos humanos (Fontamara México, 2009), 91. 
análisis de una institución completa, se limita a contenidos concretos de la norma y no a su totalidad, circunscribiendo su declaración a los aspectos particularmente impugnados, lo que provoca que se mantenga incólume la validez del resto de la norma ${ }^{83}$.

Es así que la aplicación del principio de la norma más favorable resulta compleja ante su indeterminación y la disimilitud de criterios aplicables por los órganos jurisdiccionales para determinar aquello que resulte más favorable al operario.

\section{PROPUESTA DE REVISIÓN AL SISTEMA DE COORDINACIÓN EN MATERIA DE SEGURIDAD SOCIAL.}

Los Reglamentos 883/2004 y 987/2009 han sido modificados por las siguientes disposiciones: Reglamento (CE) n. ${ }^{\circ}$ 988/2009 del Parlamento Europeo y del Consejo, de 16 de septiembre de 2009; el Reglamento (CE) n. ${ }^{\circ}$ $1231 / 2010^{84}$, del Parlamento Europeo y del Consejo, de 24 de noviembre de 2010 que extiende las disposiciones del Reglamento 883/2004 a los nacionales de terceros países que, debido únicamente a su nacionalidad, no estén cubiertos por los mismos; el Reglamento (UE) n. ${ }^{\circ}$ 1244/2010 de la Comisión, de 9 de diciembre de 2010; el Reglamento (UE) n. ${ }^{\circ} 465 / 2012$ del Parlamento Europeo y del Consejo, de 22 de mayo de 2012; el Reglamento (UE) $n .^{\circ}$ 1224/2012 de la Comisión, de 18 de febrero de 2012; el Reglamento (UE) 1372/2013 del Parlamento Europeo y del Consejo, de 19 de diciembre de 2013, y el Reglamento (UE) 1368/2014 del Parlamento Europeo y del Consejo, de 17 de diciembre de 2014.

Teniendo en consideración las diversas modificaciones que han sufrido los Reglamentos 883/2004 y 987(2009, así como debido a los resultados obtenidos, por un lado, en la consulta específica sobre la coordinación de las prestaciones de asistencia de larga duración y las prestaciones de desempleo llevada a cabo en 2013, y por otro lado, de la consulta general sobre la coordinación de la seguridad social en la UE efectuada en 2015, la Comisión Europea -como parte de un paquete de movilidad laboral- presentó el 13 de diciembre de 2016 una propuesta para la revisión de los Reglamentos $883 / 2004$ y $987 / 2009$, cuyos temas modulares son:

${ }^{83}$ Víctor Abramovich y Christian Courtis, «Hacia la exigibilidad de los derechos económicos, sociales y culturales. Estándares internacionales y criterios de aplicación ante los tribunales locales», Miguel Carbonell et al (comp.), Derechos sociales y derechos de las minorías (México, Porrúa/Universidad Nacional Autónoma de México, 2001), 208.

${ }^{84}$ El Reglamento (CE) n. ${ }^{0} 1231 / 2010$ entró en vigor a partir de enero de 2011. Con la entrada en vigor del Reglamento 1231/2010 se ha suprimido el Reglamento 859/2003. 
- La exportación de las prestaciones de desempleo durante un período mínimo de seis meses, en lugar de los tres meses actuales. Sin embargo, los Estados miembros podrán exigir que los trabajadores hayan laborado durante al menos tres meses en su territorio para poder solicitar las prestaciones por desempleo en ese país. Ante el incumplimiento de este requisito los operarios deberán acogerse a la seguridad social de su Estado de origen

- En el caso de los trabajadores transfronterizos, que viven en un país, pero trabajan en otro y regresan a casa como mínimo una vez a la semana, se propone que el Estado miembro en el que hayan trabajado en los últimos doce meses sea responsable del pago de las prestaciones de desempleo.

- Definir a las prestaciones asistenciales de duración indeterminada y los supuestos para su procedencia tratándose de los ciudadanos desplazados.

- Con base en la jurisprudencia del Tribunal de Justicia de la $U^{85}$ y en aras de evitar prácticas desleales, la propuesta de la Comisión deja claro que los Estados miembros podrán decidir no conceder prestaciones sociales $^{86}$ a los ciudadanos desplazados económicamente inactivos.

${ }^{85}$ Sentencia de 15 de septiembre de 2015 del Tribunal de Justicia de la Unión Europea. Caso Nazifa, Sonita, Valentina y Valentino Alimanovic vs Jobcenter Berlin Neukölln Asunto C- 67/14 se determina que un Estado miembro puede excluir de determinadas prestaciones sociales de carácter no contributivo a los ciudadanos de la UE que se desplazan a dicho Estado en busca de trabajo; [Consulta: 26 de enero de 2017], disponible en $<$ http://curia.europa.eu/juris/document/document_print.jsf;jsessionid=9ea7d2dc30ddbfd 571a919b64e08a0a0b473a805d030.e34KaxiLc3qMb40Rch0SaxuPbN10?doclang=ES\&t $\mathrm{ext}=\&$ pageInde $=0 \&$ part $=1 \&$ mode $=$ DOC \&docid $=163254 \&$ occ $=$ first $\&$ dir $=\& \mathrm{c}$ $\mathrm{id}=41645>$. Sentencia de 11 de noviembre de 2014 del Tribunal de Justicia de la Unión Europea. Caso Elisabeta Dano y Florin Dano vs. Jobcenter Leipzig, Asunto C-333/13 se determina que los ciudadanos de la Unión económicamente inactivos que se desplacen a otro Estado miembro con el único fin de beneficiarse de ayudas sociales podrán ser excluidos de determinadas prestaciones sociales; Sentencia de 25 de febrero de 2016. [Consulta: 26 de enero de 2017], disponible en <http://curia.europa.eu/juris/document/document. jsf?docid=159442\&doclang=ES $>$. Sentencia de 25 de febrero de 2016 del Tribunal de Justicia de la Unión Europea Caso Jovanna García-Nieto vs Vestische Arbeit Jobcenter Kreis Recklinghausen. Asunto C-299/14, se confirma que pueden denegarse a los nacionales de otros Estados miembros determinadas prestaciones sociales durante los tres primeros meses de su estancia. [Consulta: 26 de enero de 2017], disponible en $<$ http://curia. europa.eu/ju ris/document/document.jsf?text $=\&$ docid $=174589 \&$ pageIndex $=0 \&$ doclang $=$ es\&mode $=1$ st \&dir $=\&$ occ $=$ first $\&$ part $=1 \&$ cid $=574127>$

${ }^{86}$ La legislación comunitaria ha dispuesto que las prestaciones sociales son beneficios proporcionados de acuerdo con la legislación de seguridad social de los Estados miembros en las ramas de enfermedad, maternidad y de paternidad asimiladas; pensiones de vejez, prestaciones de jubilación anticipada y la invalidez; prestaciones de superviven- 
- La armonización de las normas jurídicas en materia de seguridad social con la sentencias pronunciadas por el Tribunal de Justicia de la Unión Europea, las que en su mayoría, en su calidad de fuentes subsidiarias del Derecho de Unión se han encargado de subsanar las lagunas de los Derechos primario y secundario.

- El reforzamiento de las disposiciones administrativas sobre coordinación de la seguridad social en el caso de los trabajadores desplazados. La modificación propuesta por la Comisión Europea intenta garantizar que las autoridades nacionales dispongan de los instrumentos adecuados para comprobar el estatuto de los trabajadores desplazados en materia de seguridad social y establece procedimientos más claros para la cooperación entre los Estados miembros a la hora de tratar los posibles casos de prácticas desleales y abusos.

Evidentemente la propuesta descrita muestra la necesidad de materializar la simplificación de la normativa que debiera imperar en el ámbito de la coordinación de los sistemas de seguridad social. Lamentablemente en contravención a la naturaleza y principios del derecho social, del cual forma parte el derecho de la seguridad social, la naturaleza extraordinariamente técnica y complicada del marco legislativo existente aunada a las múltiples modificaciones y la vasta jurisprudencia del Tribunal de Luxemburgo han dificultado la determinación, interpretación y aplicación de las normas en materia de seguridad social ante el ejercicio del derecho a la libre circulación.

Resulta necesaria la simplificación de la normativa que integra el sistema de coordinación en materia de seguridad social y la clarificación de situaciones, posiciones, definiciones y ámbitos de su aplicabilidad, acompañada de una mayor información sobre los derechos que confiere la legislación comunitaria, pues de esta forma se facilitará su ejercicio y se incrementaran las oportunidades para lograr la movilidad efectiva y la estabilidad económica sin detrimento de los derechos sociales de los grupos vulnerables destinatarios del régimen de seguridad social que resulte aplicable.

\section{FUENTES DE INFORMACIÓN}

Abramovich, Víctor y Courtis, Christian, Hacia la exigibilidad de los derechos económicos, sociales y culturales. Estándares internacionales y criterios de aplicación ante los tribunales locales, en CARBOnell, Miguel et al (comp.), Derechos sociales y derechos de las minorías, México, Porrúa, Universidad Nacional Autónoma de México, 2001.

cia y de defunción; beneficios de desempleado; prestaciones familiares; prestaciones en caso de accidentes de trabajo y enfermedades profesionales. 
Acta Única Europea. [Consulta: 28 de enero de 2017], Disponible en: https://www. boe.es/

boe/dias/1987/07/03/pdfs/A20172-20182.pdf

BAZÁN, Víctor y JiMENA QUESADA, Luis, Derechos económicos, sociales y culturales. Cómo se protegen en América latina y en Europa, Argentina, Astrea, 2014.

Bonnet, RENE, Conflits entre les droits nationaux et les instruments internationaux dans Ie domaine de la securite sociale, Techniques, Juris-Classeur,. Droit international. 1993 . Fascicule 578.

Carta de los Derechos Fundamentales de la Unión Europea [Consulta: 22 de enero de 2017], Disponible en: http://www.europarl.europa.eu/charter/pdf/text_es.pdf

Corti VARElA, Justo, La propuesta de seguro de desempleo europeo. Estado de la cuestión, en CHOCRÓN GIRÁLDEZ, Ana María et al., (coord..), El derecho del trabajo y la seguridad social en la encrucijada. Retos para la disciplina laboral, España, Laborum, 2015.

COURTIS, Christian, El mundo prometido. Escrito sobre derechos sociales y derechos humanos, México, Fontamara, 2009.

GÁRATE CAStro, Javier, Transformaciones en las normas comunitarias sociales, en Los mercados laborales y las politicas sociales de Europa. XX Congreso Nacional de Derecho de Trabajo y de la Seguridad Social, Logroño 28 y 29 de mayo de 2009, Ministerio de Trabajo e Inmigración. Subdirección General de Información Administrativa y Publicaciones.

GuAmán HernándeZ, Adoración, Estado Social y Unión Europea: el conflicto permanente, [Consulta: 28 de enero de 2017], Disponible en: https://www.researchgate. net/profile/Adoracion_Guaman/publication25/9356604_Estado_social_y_Union_ Europea_el_conflicto_permanente/links/02e7e52b2af0 d8 $32 e 60 \overline{0} 0000 . \overline{p d} \bar{f}$

MANRIQUe LóPEZ, Víctor Fernando, «La normativa comunitaria actualmente vigente en la Unión Europea, Revista de la Universidad de Deusto, segunda época, fascículo 116, volumen 54/1, enero-junio 2006, Bilbao.

Miranda Boto, José María, «El Estadio Previo: Algunos Problemas Terminológicos de la Seguridad Social Comunitaria» en: VV.AA.; El Reglamento Comunitario. Nuevas Cuestiones. Viejos Problemas. Laborum. Murcia. 2008.

Muñoz Machado, Santiago y Lorenzo, Rafael de, Política social de la Unión Europea en materia de minusvalías, Madrid, Escuela Libre, 1997.

Palavecino CÁceres, Claudio, Los principios del derecho del trabajo, [Consulta: 2 de febrero de 2017], Disponible en: https://www.u-cursos.cl/derecho/2012/2/ D128A0523/2/material_docente/bajar?.

Reglamento 883/2004 [Consulta: 27 de enero de 2017], Disponible en: eur-lex.europa.eu/LexUriServ/LexUriServ.do?uri=OJ:L:2004:166:0001:0123:es:PDF

SÁnchez-RodAs NAVARro, C., La aplicación del derecho comunitario a las prestaciones especiales no contributivas, Comares, Granada, 1997.

— Sinopsis del Reglamento 883/2004 y del Convenio Multilateral Iberoamericano de Seguridad Social, en Chocrón GIRÁldez, Ana María et al., (coord..), El derecho del trabajo y la seguridad social en la encrucijada. Retos para la disciplina laboral, España, Laborum, 2015. 
Análisis crítico del capítulo 8 del Reglamento 883/2004, Revista General de Derecho del Trabajo y Seguridad Social, número 32, [Consulta: 26 de enero de 2017], Disponible en: http://www.iustel.com

Tratado Constitutivo de la Comunidad Europea del Carbón y e1 Acero. [Consulta: 20 de enero de 2017], Disponible en: https://www.boe.es/legislacion/enlaces/documentos/uel

Tratados(0397-0475).pdf

Tratado de Roma, [Consulta: 28 de enero de 2017], Disponible en: https://www.pnsd. msssi.

gob.es/pnsd/legislacion/pdfestatal/i12.pdf

Tratado de Maastricht [Consulta: 13 de enero de 2017], Disponible en: http://www. pnsd.msssi.gob.es/pnsd/legislacion/pdfestatal/i77.pdf

Tratado de Ámsterdam [Consulta: 26 de enero de 2017], Disponible en: https://europa.eu/european-union/sites/europaeu/files/docs/body/treaty_of_amsterdam_ es.pdf

Tratado de Niza [Consulta: 13 de enero de 2017], Disponible en: https://www.ecb. europa.eu/ecb/legal/pdf/es nice.pdf

Tratado de la Unión Europea, [Consulta: 2 de febrero de 2017], Disponible en: http:// www.boe.es/doue/2010/083/Z00013-00046.pdf

Tratado de Funcionamiento de la Unión Europea [Consulta: 24 de enero de 2017], Disponible en: https://www.boe.es//doue/2010/083/Z00047-00199.pdfu 